\title{
Resistance, the Echo of Change
}

\author{
Wenhe Yue \\ School of Management, Shenyang Jianzhu University, Shenyang 110168, China \\ E-mail: bobo1012@ sina.com
}

\begin{abstract}
Change can be seen everywhere, and all people and organizations are affected by change more than ever before. This article aims to identify the resistance to change, illustrate these resistance changes. Finally, give some recommendatory practices might managers adopt to improve the prospect of successful change implementation.
\end{abstract}

\section{Keywords: Resistance, Change, Organization}

In the new century, when business and political leaders-indeed, entire governments-assert their dedication to change, but how to manage the reactions to that change may be the greatest challenge. Change creates anxiety, uncertainty and stress, even for those managing change, and even of they are fully committed to change (Carnall, 1990, p.138). These reactions often are lumped under "resistance" to change. Resistance is habitually a reaction to a loss of control, not necessarily to the change itself. The less knowledge for a person to know the rational for the change and the implications of the change and how to operate the change, the greater the threat to that person's control over his or her environment (Jick and Peiperl, 2003). Resistance to change seems to be always more powerful in strategic changes (Del Val and Fuentes, 2003)

But now with the increase of echoes of change, resistance need not be frightening under the wisely management. Manager trying to improve processes in their organizations need to understand why people resist change, and this is just a good information resource for them to control the processes (Jager, 2001, p.24).

\section{What is the resistance?}

Resistance at its most obvious is a slow motion response to meet agreements or even a complete refusal to cooperate with change. It can either be intentional or unintentional, covert or overt (O'Connor, 1993, p.30).

Vakola cited Burnes (1992) that resistance to change is a critical issue in all change initiatives because it may lead to a lack of co-operation and communication among those involved and affected by the change process.

Resistance is sometimes portrayed by consultants and managers as the result of employee weakness, and individuals may be stereotyped and called saboteurs, shirkers, dinosaurs, ostriches, loony lefties, and loss of morale, distrust, becoming self-centered, narrow-minded and so on (Cascio, 1993).

In the organizations, employees will often psychologically resist change when it involves altering their work values and self-concept; some professionals find marketing and administration duties unsatisfying when they take up time that could have been spent executing professional work (Whittington, McNulty and Whipp, 1994).

Many professionals in the public and in the private sector are facing increased responsibility for marketing and administration and some of them are unsure how much of their newly defined role they should accept their reluctance to change is partly a consequence of their occupational commitment to professional work; their unwillingness to take on more duties is rarely just a case of irrational resistance (Morris and Pinnington, 1998)

\section{Why resistance to change}

As mentioned before, resistance is a natural phenomenon in change progress. The failure of many large-scale corporate change programs can be traced directly to employee resistance (Maurer, 1997). During 1993 and 1996 , 500 large Australian organizations revealed that employee resistance was the most frequently cited implementation problem encountered by management when introducing change (Bovey and Hede, 2001). Why is there resistance to change in the organization? And what then are the sources of resistance to organizational change?

Ford, Ford and McNamara (2002) explained that resistance occurs because it threatens the status quo, or increases fear and the anxiety of real or imagined consequences including threats to personal security and confidence in an ability to perform. In addition, Change threatens the way people make sense of the world, calling into question their values and rationality, and prompting some form of self-justification or defensive reasoning. Or, people distrust or have past resentments toward those leading change; they have different understandings or assessments of the situation, or are protecting established social relations that are perceived to be threatened.

Resistance to change occurs when it creates too much role incompatibility for employees. Expecting shop-floor workers to communicate with a larger number of teams and managers in the plant will mean they have to adopt a broader role set; that is, they will have to cooperate with various groups and learn to behave and respond to different 
expectations. Some employees will find developing a broader set of relationships at work to be a stimulating new challenge and personally fulfilling; however, others may find these new relationships to be incompatible with their more restricted concept of self, and experience increased role strain and stress. People who are "resistant" are not necessarily being stubborn but may be slower in having "insight" into the situation (Pinnington and Lafferty, 2003)

Effective change has been characterized as unfreezing old behaviours, introducing new ones, and re-freezing them (Appelbaum and Wohl, 2000). Change is difficult and threatening. It is natural for change to be met with resistance people resist things they are unsure of. The bigger of change, the greater resistance to create change (Maurer, 1998). People resist change due to many factors, some of which are a lack of information on the proposed change and a comfort in the stable environment to which they have become accustomed and in which they find predictability and security (Weiss, 1998). As an example, aging baby-boomers are moving into risk-averse zones. Facing personal, financial and career changes, they want change without high risk (Tapsell, 1998). Effective strategic change requires approaches to leadership that are more likely to enhance workplace change through employee participation, motivation and commitment. Change can only succeed if it is based solidly on an understanding of how people behave, what motivates them, and how improved positive attitudes can be developed (Zeffane, 1996).

Bennis (1973, cited in Coghlan, 1993, pp.10-11) suggests six types of response that individuals may mobilize: oppose, resist, tolerate, accept, support and embrace. Since every change involves some forms of loss and disappearance of something familiar, the choice of these responses is affected by the degree of ambiguity of the change, the degree of control over the change and environment, the degree of trust in the change initiators. Meet with organizational changes, employees often wonder what the goal of the change is, why need to change, what benefits it brings to company and to me, and what affects my own work and job development etc, because changes requires going from the known to the unknown (Bovey \& Hede, 2001, p.534). Lack in satisfying information and understanding of change, change may be misunderstood, and at the same time all kinds of different attitudes will appear, besides acceptance and support, suspicion, disbelief, refusal, and denial will also be shown in front of managers. And thus, resistance emerges.

Understanding the sources of resistance allows creation of a management strategy to deal with it. To resolve resistance, a manager must willingly explore what causes it. There is no other way. O'Connor (1993) believes that resistance results from differences involving ideas, motives, plans, or priorities, and brought forward five common sources of resistance as follows:

(1) Lack of belief that there is a serious need for change.

(2) Different descriptions of the need for change.

(3) No agreement about goals for change.

(4) Lack of belief that the goal is attainable.

(5) No confidence in the manager of change.

Recognizing the sources of resistance guides the development of better understanding. And once a source of resistance is identified, managers can encourage the debate of issue about the identified source and work to integrate these differences and therefore minimize resistance.

\section{Resistance, as enemy in change}

In recent society, change is considered as inevitability for many organizations. However, nearly two-thirds of major change programs prove unsuccessful and, according to Fortune 500 executives, the primary reason for this is not a lack of skill or resource, but resistance (Anonymous, 2002, p.21). Resistance is therefore understood to be the enemy of change.

\subsection{Rational vs. Irrational Resistance}

Rational resistance can occur where an individual's own rational assessment of change outcomes differ from these of management. So it can be overcome with reasonable explanation for any proposed change (Jager, 2001, p.26). If the reasons to change are persuasive enough, then resistors will willingly adopt the change.

Taking on something new largely means giving up something that is familiar, comfortable and predictable, so people will feel that they are uninvolved in new process. Another rational reason why people resist change is that they fear having to learn something new. Sometimes it is not that they disagree with the benefits of some new process; rather, they simply fear the unknown future and doubt their ability to adapt to it (Davidson, 2002, p.21). In another words, it means fear may stop people from taking first steps to change, even when they know that the result of change will greatly benefit them.

However, irrational resistance does exist, too. It means individual reaction to change is also a function of 
predispositions and preferences not necessarily based on a rational assessment of change (Anonymous, 2002, p.22). Simply speaking, there are a few people never accept change, even if evidence, proof, demonstration, or persuasion are urging them to willingly adopt the change. They simply don't want to change, and they always find a problem with any changes. According to Geisler (2001), these people are so-called bottom-feeders, who seem to be the most dissatisfied and the most vocal. Resistance therefore becomes an enemy that is a serious preventer in the change process, and hard to conquer.

\section{Resistance, as assistance in change}

Usually, resistance is regarded as an obstacle that prevents change process from successful developing. So people always try to compete with it until diminishes. But in fact, as an essential element in understanding any change progress, it is not totally passive, but is rather a powerful, effective, and dynamic energy. Handled properly, it can serve as a valuable assistance and contribution to the change process (Coghlan, 1993, p.11; Heifetz \& Linsky, 2002, p.69; Jager, 2001, p.24). But it should be remembered that it is a fallacy to consider change itself to be inherently good, because change can only be evaluated to be good or not through its consequences until sufficient time has passed (Anonymous, 2002, p.22).

Appearance of resistance may mean an influx of energy added into the change process. Those employees who resist plan for change may in fact have different definitions of the problem or beliefs about its seriousness. Monitoring these different responses and listening to them will make managers aware of the issues that need to be addressed during the change process (Freda, Arn \& Gatlin-Watts, 1999, pp.32-33). There is a real danger of apathy when dealing with significant program where resistance occurs. It is impossible for managers to examine more closely the sources of the existing problems, which means latent crisis to change in the long run. In this respect resistance can become a useful source of innovation. Furthermore, without resistance, any proposal favoured by managers will be accepted, which can be detrimental to lead to an organizational change limitation (Anonymous, 2002, p.23).

CEO of Belgian Telecommunication Co. (Vas, 2001, p.84) has said in an interview that resistance sometimes is not against change; it means a shortage of personnel, unready process and unsuccessful data processing on time that is what people criticize, not in itself. In other words, resistance reveals defects behind of an organization, and assists to find out better resolvents. As a result, more and more major organizational changes or innovations start to anticipate resistance, especially if proposed changes alter values and visions related to the existing order (Trader-leigh, 2002, p.139). All in all, facing resistance, we cannot deny and reject it blindly, but listen, learn, understand and lead it.

\section{How to overcome the resistance}

King and Anderson cited Kotter and Schlesinger (1979) that there are six strategies overcoming the resistance: communication, participation, facilitation, negotiation, manipulation and coercion.

\subsection{Facilitation}

Many organizations still believe that their success depends largely on the commitment of their employees (Emshoff, 1994). Appelbaum and Wohl cited Dowd (1998) that managers must provide support during the change process. Making oneself available, providing adequate information, being positive, actively listening, and showing personal interest and respect are strategies that mangers can use to help minimize the frustration of those coping with change. The manager should try to preserve the dignity of those negatively affected by change and help staff to find an outlet for their anger and frustration. The manager must also recognize that employees may suffer a sense of loss during a change process and that change may be painful. A supportive approach by the manager can minimize these elements that may increase resistance to the change. For example, in downsizing organizations, for the laid-off worker, organizations can provide help in outplacement services, redeployment. Meanwhile, the surviving employees will act as they see appropriate according to how the organization treated its laid off workers. When they perceived that layoff victims had been properly taken care of, they reacted positively, then performing as well as they had and feeling as loyal as the organizations as before (Appelbaum, Everard and Hung, 1999)

\subsection{Participation}

Employees should be involved in decision-making and new program development. It is one of the best methods of handling resistance, simply because that employee involvement in the stage of a change process significantly influences the eventual outcome. Change has a significant impact on the work that people do, will have a significant impact on their self-esteem (Carnall, 1990, pp.138-141). People will feel better about a decision in which they played a part, because they experience a sense of ownership that are likely to creatively change aspects of their organizations to solve problem and to exert extra effort to develop their products or services (Dirks, Cummings \& Pierce, 1996). Thus their self-esteem will be enhanced to a certain height, and they won't show resistance to change any more, even they will feel angry to others who disagrees the change process they participate in. 
Murer (2002) suggested that adapting to change in the organization is not a solo effort. It is a team sport that requires the involvement of many people. Although it is very popular that manager or boss must lead change, many change programs fails because of employees' resistance as mentioned before. Representatives from different departments in an organization should be brought together to discusses and make suggestions for improvement. At the same time, boss or manager should listen carefully to the responses, and then get interested employees involved in designing the program (Smith 1993). As a result, negative attitudes of employees to the new program will be eliminated, especially when some of their suggestions or advices have been adopted, because they feel a sense of worth, which is a basic human need (Pihulyk, 2002).

\subsection{Communication}

Communication is the key to the survivors' understanding the new corporate strategy and their accurate interpretation of the organization's goals and objectives. The more information is made available, the better cope with the new situation. Further open communication will also be effective in reducing employee resentment and resistance. Communicating what is known and asking for employees to do the best with what information is available will help minimize conflict and promote change. An effective and comprehensive communications plan, with feedback loops for employees to air their concerns, must be in place from day one (Attaran, 2000).

Managers should let staff know bad news rather than manipulate it into good news. Effectively communicating the change process aids in maintaining positive staff morale during the change (Sherer, 1997). People are trying to find out facts during transitions. If communication is frequent, open, and honest, even fuzzy answers are appreciated. When change is imminent, people want to know the specifics of any change ----- why, who, what, when and how---till they believe that useful change is possible, or they will not make the sacrifices required of the change process (Axley, 2000, pp.21). The question he suggested as followed.

Why?

Why is the change needed?

Why is the change needed in this way, at this time and place?

What?

What is the change and what preparation is needed for it?

What processes, structure, goal, and standards will be affected by the change?

What will successful change look like?

What does the change mean to those affected by it?

Who?

Who will be affected by the change?

Who should have input to the changes processes?

How?

How will the change proceed and affect the organization?

How can we help facilitate the change?

How will we know if the change has been successful?

When?

When will key changes take place?

When should messages about the change be communicated?

The above questions about $4 \mathrm{Ws}+1 \mathrm{H}$, which are just a part of questions should be asked before a change will be launched. And these questions raised here can help serve as useful guides in creating the communication, which is the first important step in any endeavour. In the two-way communication both management and employees can voice their opinions, concerns, desires and provide information.

\subsection{Negotiation}

Negotiations with individuals involved and the forces imposing the change can minimize resistance to change. When this is a possible, individual involved in the change will feel they have some control and be more likely to view the change as palatable. Providing as many avenues as possible for staff to provide input, help make decisions, and have some control over matters that affect them facilitates change. Furthermore, spreading the change out over time can also reduce the trauma of change. Time can allow the individual to move through a grief process slowly 
and experience it less intensely (Dowd, 1998)

\section{Conclusion}

In recent society, change is considered as inevitability for many organizations. Resistance to change is an essential factor to be considered in any change process, since a proper management of resistance is the key for change success or failure. Resistance is a natural and normal response to change because change often involves going from the known to the unknown (Coghlan, 1993). Resistance is a powerful organizational force. Although it is impossible to eliminate the resistance, it still needs to set up a better way to manage the resistance and try to minimize it. Use the knowledge to confront it. To begin with, educating employees can make them understand their roles and functions in making change happen. In addition, when the managers will do more clear and honest communication throughout the organization, which can be in reducing anxiety and harnessing assistance at all levels. What is more, foster and create employees to test the new change and give some recommendations with the new way of operating. Motivating and retaining employees' opportunities to participate in decision is an important aspect. Further more; managers are not only responsibility to the company, but also to the employees. It is better for them to negotiate with the employees and try to make agreement. Finally, using some manipulation and coercion strategies can identify and overcome potential sources of resistance as well and make the organization survive and thrive.

\section{References}

ANonymous. (2002). Resistance to change: Enemy or ally? Strategic Direction. Vol.18, No.6, pp.22-23.

Appelbaum, S.H. and Wohl, L. (2000). Transformation or change: some prescriptions for health care organizations. Managing Service Quality., Vol.10, No.5, pp. 279-98.

Appelbaum, S.H., Everard, A. and Hung, L.T.S. Strategic downsizing: critical success factors. Management Decision. Vol.37, No.7, pp. 535-552.

Attaran, M. (2000). Why does reengineering fail? A practical guide for successful implementation. The Journal of Management Development, Vol.19, Iss.9/10, pp. 794.

Axley, S.R. (2000). Communicating change: Questions to consider. Industrial Management. Vol.42, No.4, pp.20-21.

Bennett, J.L. (2001). Change Happens. HR Magazine. Vol.46, No.9, p.152.

Bovey, W.H., and Hede, A. (2001). Resistance to organisational change: the role of defence mechanisms. Journal of Managerial Psychology. Vol.16, No.7, pp. 534-548.

Carnall, C.A. (1990). Managing Change in Organization, Prentice Hall, London, UK.

Casciom W.F. (1993). Downsizing: what do we kNow? What have we learned? Academy of Management Executive. Vol.7, No.1, pp.95-104.

Coghlan, D. (1993). A person-centred approach to dealing with resistance to change. Leadership \& Organization Development Journal, Vol.14, No.4, pp. 10-14

Davidson, J. (2002). Overcoming resistance to change. PM. Public Management, Vol.84, No.11, p.21.

Del Val, M. P. and Fuentes, M. (2003). Resistance to change: a literature review and empirical study. Management Decision. Vol.41, No.2, pp. 148-155.

Dirks, K.T., Cummings, L.L. \& Pierce, J.L. (1996). Psychological ownership in organizations: Conditions under which individuals promote and resist change. Research in Organizational Change and Development, Vol.9, p.8.

Dowd, S.B. (1998). Helping staff cope with change. Hospital Material Management Quarterly, Vol.20, No.1, pp. 23-8.

Emshoff, J. R., (1994). How to increase employee loyalty while you downsize. Business Horizon, Vol.37, No.2, pp. 49-57.

Ford, J. D., Ford, L.W. and McNamara, R.T. (2002). Resistance and the background conversations of change. Journal of Organizational Change Management. Vol.15, No.2, pp. 105-121.

Freda, G.G., Arn, J.V. \& Gatlin-Watts, R.W. (1999). Adapting to the speed of change. Industrial Management, Vol.41, No.6, pp.32-33.

Geisler, D. (2001). Bottom-feeders: People who reject change. Executive Excellence. Vol.18, Iss.12, p.19.

Heifetz, R.A. \& Linsky, M. (2002). A survival guide for leader. Harvard Business Review, Vol.80, No.7, p.69.

Jager, P.D. (2001). Resistance to change: A new view of an old problem. The Futurist. Vol.35, No.3, p.24.

Jick, T.D. and Peiperl, M.A. (2003). Managing Change: case and concepts, $2^{\text {nd }}$ edn, McGraw Hill/Irwin, New York, 88 
pp. xxi

King, N., and Anderson, N. (1995). Chapter 8. Resistance to change. InNovation and Change in Organizations, pp. 156

Maurer, R. (1997). Transforming resistance. HR Focus, Vol.74, No10, pp. 9-10.

Maurer, R. (1998). Is it resistance, or isn't it?. Management. Vol.50, No.1, pp. 28-9

Maurer, R. (2002). When people are ready to act. The Journal for Quality and Participation, Vol.25, No.3, p.24.

Morris, T. J. and Pinnington, A. H. (1998). Promotion to partner in professional firms. Human Relations, Vol.51, No.1, pp.3-24

O'ConNor, C.A. (1993). Resistance: The repercussions of change. Leadership \& Organization Development Journal. Vol.14, No.6, p.30.

Pihulyk, A. (2002). Understanding needed to overcome resistance to change. Canadian HR Reporter, Vol.15, iss.9, p.4.

Pinnington, A. and Lafferty, G. (2003). Chapter 9. Managing People. Human Resource Management in Australia, Oxford New York

Sherer, J. (1997). The human side of change. Healthcare Executive, Vol.12, No.4, pp. 8-14

Smith, P.G. (1993). Why change is hard. Across the Board. Vol.30, No.1, p.55.

Tapsell, S. (1998). The challenge of change and fear of the unkNown. Management, Vol.45, No.7, pp. 60.

Trader-leigh, K.E. (2002). Case study, Identifying resistance in managing change. Journal of Organization Change Management, Vol.15, Iss.2, p.139.

Vakola, M. (2000). Exploring the relationship between the use of evaluation in business process re-engineering and organisational learning and inNovation. The Journal of Management Development, Vol.19, iss.9/10, pp812

Vas, A. (2001). Top Management Skills in a Context of Endemic Organizational Change: The Case of Belgacom. Journal of General Management. Vol.27, No.1, p.84.

Weiss, W.H. (1998). Change: how to bring it about and meet its challenge. Supervision, Vol.59, No.8, pp. 9-10

Whittington, R., McNulty, T,.and Whipp, R. (1994). Market-driven change in professional service: problems and processes. Journal of Management Studies, Vol.31, No.6, November, pp.829-45

Zeffane, R. (1996). Dynamics of strategic change: critical issues in fostering positive organizational change. Leadership \& Organization Development Journal, Vol.17, No.7. 